De zaak is gevestigd in een provinciale stad en heeft \pm 250 afnemers, grootendeels in de dorpen in de omtrek van de stad. De afnemers worden bezocht door vier reizigers, die elk een auto te hunner beschikking hebben.

De reizigers vervoeren zelf voor een groot deel de goederen met hun auto en hebben van de meest courante goederen steeds eenige voorraad ter onmiddellijke aflevering. De verkoop geschiedt als regel op één crediet, maar in ongeveer $25 \%$ der gevallen tegen contante betaling.

Er worden \pm 1200 artikelen verkocht.

De prijzen waartegen ze worden verkocht, worden elke week opnieuw vastgesteld. De reizigers ontvangen elke week een verbeterde prijscourant.

De administratie bestaat uit een inkoopboek, verkoopboek, kas-, bank- en giroboek en een debiteuren- en crediteurenboek, benevens journaal en grootboek. $\mathrm{Er}_{r}$ is geen magazijnadninistratie. In- enl verkoopboeken bevatten alleen de naam en het bedrag. Zoowel de inkoopfacturen als de copie-verkoopfacturen zijn chronologisch opgeborgen en genummerd. De nummers zijn in het verkoopboek en het inkoopboek vermeld.

Bij het constateeren van de annwezige voorraad goederen kan cén van Uw assistentell aanwezig zijn.

Teneinde een overzicht te hebben over de verkoop is de inventarislijst als volgt ingericht:

a. Beginvoorraad

b. Ingekocht

c. Verkocht

d. Eindvoorraad

e. Eenheidsvoorraad

f. Bedrag.

De hoeveelheid, bedoeld onder $b$ wordt getrokken uit de inkoopfacturen, de hoevelheid bedoeld onder $c$ wordt afgeleid uit de kolommen $a, b$ en $d$

Gevraagd:

a. nitvoerig te beschrijven hoe Ge bij de bestaande administratie de controle op de goederenheweging zult nitvoeren.

b. of de bestaande administratie het naar $U w$ meening al dan niet noodig maakt Uw verklaring bij de balans voor dit jaar van ce!n voorbehoud te voorzien.

c. welke verbeteringen $\mathrm{Gij}$ in de administratie der goederenbeweging ten behoeve van $U_{W}$ controle noodig of wenscluelijk vindt en welke invloed deze verbeteringen op de techniek Uwer controle zullen hebben.

Vrijdag 14 December 1934 ,

$14-15.30$ uแr.

Vraagstuk No. IIII.

CONTINGENTEERING.

\section{Vraag A.}

N.V. "A" en N.V. „B" hebben een overkomst gesloten ter contingenteering van hun omzetten en wel naar verhouding van de hoeveelheden, die door elk van hen in een basisjaar zijn verkocht.

N.V. A" produceert zelf.

N.V. "B" betrekt het product van een fabriek die deel uitmaakt van hetzelfde concern als waartoe N.V. "B" behoort. Bedoelde fabriek is in een ander land gelegen. N.V. „A" en "B" verkoopen alleen in het binnenland, en wel twee producten; de overeenkomst strekt zich tot beide producten uit.

Accountant $X$ ontvangt de opdracht de omzetten van de N.V. „A", accountant $Z$ de omzetten van N.V. „B" over het basisjaar vast te stellen. Beiden hadden tot heden geen relatie met deze N.V.'s, noch met het ter sprake gekomen concern.

Geef aan op welke wijze de accountants aan de verlangde basisomzetten zullen komen, op welke punten zij bedacht zullen zijn bij de vorming van hun oordeel over de juistheid van bedoelde gegevens, en hoe zij zicl daaromtrent een oordeel kunnen vormen.

\section{Vraag B.}

In latere jaren ontvangen de bedoelde accountants telkens de opdracht controle uit te oefenen of de opgaven van de verkochte hoeveelheden welke N.V. "A" en N.V. „B" aan elkaar hebben verstrekt. juist zijn.

Geef aan op welke punten de accountants bij deze controle hun aandacht zullen vestigen.
Vervolg vraagstuk No. 3.

Vrijdag 14 December 1934,

$$
15.30-17 \text { t1ur. }
$$

Tijdens de controle bij de vorige vragen bedoeld, rijst de volgende moeilijkheid:

Accountant $Z$ heeft bij de N.V. „B” de omzetten vastgesteld uit het verkoopboek, heeft contrôle uitgeoefend met copie-facturen, heeft nagegaan aan de hand der expeditie-adninistratie, dat geboekte verkoopen ook verzonden zijn, zulks speciaal voor de verkoopen, die in de laatste weken van het boekjaar zijn geboekt, heeft vastgesteld dat verkoopen bijna alle zijn afgerekend en dat voor enkele thans nog onbetaalde aannemelijk is dat afrekening $110 \mathrm{~g}$ niet plaats vond.

$Z$. wil nu controleeren of de omzetcijfers aansluiten bij de cijfers der inkoopen van de fabriek rekening houdend met begin- en eindvoorraad. Van elke aflevering, die de fabriek deed, werd door haar ingediend een afleveringsbriefje zonder geldbedragen en een rekening (doorslagen). De Directie van N.V. „B" weigert aan den accountant de rekeningen ter inzage te geven, aangezien daaruit de prijzen blijken en aangezien accountant $X$ (een Duitsch accountant) bij N.V. "A" zich ook beperkte tot contrôle van verkoop en aflevering en zich niet inliet met productic-contrôle.

Geef gemotiveerd aan:

10 of $U$ het standpunt van $X$ dan wel van $Z$ juist acht.

2o of $Z$ eventueel genoegen kan nemen met de afleveringsbriefjes dan wel groote waarde moet hechten aan het werken net de facturen.

\section{REPERTORIUM VAN TIJDSCHRIFT-LITERATUUR OP HET GEBIED VAN ACCOUNTANCY EN BEDRIJFSHUISHOUDKUNDE}

Redactie: Mej. Dr. R. PHILIPS en Drs. G. L. GROENEVELD voor bedrijfseconomie en J. P. DE HAAN en J. C. SPANGENBERG voor accountancy

\section{A. ACCOUNTANCY}

\section{HET ACCOUNTANTSBEROEP}

Training for the accountancy profession

W it t y, R. A. - Bespreekt o.a. de vooruitzichten voor het accountantsberoep en de theoretische en praktische bekwaamheden, welke een accountant dient te bezitten.

A II 3 The Incorporated Accountants' Journal Dec. 1934

\section{Education for professional accountants}

$\mathrm{N}$ is s le y, W. W. - Uitvoerig wordt de opleiding voor het accountantsberoep besproken. Geconstateerd wordt, dat de C.P.A. examens weliswaar de vaktechnische eischen der candidaten behoorlijk toetsen, maar dat de algemeene intellectueele ontwikkeling zeer weinig wordt onderzocht. Gegeven worden statistieken betreffende vooropleiding van candidaten, terwijl tenslotte academische opleiding wordt bepleit.

A II 3

The Journal of Accountancy Januari 1935

\section{LEER VAN DE INRICHTING}

Incassokosten en de verantwoording hiervan bij gemeentebedrijven

D is p e n, P. H. - Schr. werkt een verantwoording uit, waarbij gebruik gemaakt wordt van incasso-zegels en van een tusschenrekening incasso-kosten.

A III 3

Financieel Overheidsheheer 15 November 1934

Nieuws van de I.B.A.

Starteveld, IR. W. - Beschrijft de op de I.B.A. uitgekomen nieuwe vindingen op het gebied van administratieve en mechanische hulpmiddelen.

A III 3 Administratieve Arbeid October/November/December 19.34

\section{LEER VAN DE CONTROLE}

How accountants can serve municipalities

Ch a t t e rs, C. H. - Het constateeren van en rapporteeren over te juistheid van de jaarrekening is niet voldoende. Conclusies en adviezen moeten worden gegeven; accountantsrapporten moeten ee! bron van informatie en tevens een basis voor het toekomstig beheer. vormen.

A IV 2

The Journal of Accountancy Januari 1935 
Practice onder the securities act of 1933 and the securities exchange act of 1934

Starkey, R. F. en Henderson, A. I. - Dit onderwerp wordt behandeld uit het gezichtspunt van een accountant en van een „Aitorney".

A IV 2

The Journal of Accountancy December 1934

Organisation of accountant's offices

Dolby, Ch. M - In het bijzonder worden behandeld de correspondentie afdeeling en de door accountantskantoren te houden boeken (cliëntenregister e.d.g.)

A IV 4

The Incorporated Accountants' Journal Jan. 19.35

\section{B. BEDRIJFSHUISHOUDKUNDE}

\section{a. ALGEMEENE BEDRIJFSHUISHOUDKUNDE}

IV. LEER VAN DEN KOSTPRIJS EN DE PIRISVORMING

Invloed van tarief op (munt) gasgebruik

Voogd, ir. J. G. en ir. D. T inbergen - Op grond van statische analy'se concludeeren schrijvers, dat het verband tusschen gemiddeld gasverbruik en gasprijs zoodanig ligt, dat de gemiddelde muntgasverbruiker per jaar ongeveer eenzelfde bedrag afneemt, welk ook het gastarief is.

B a IV 9

Gasbelangen 20 Januari 1935

\section{LEEIR VAN DE ORGANISATIE}

\section{Over enkele productiewetten in de industrie}

E y k, ir. H. H. W. van - Schr. beliandelt het probleem, hoe het productie-resultaat varieert, indien men een der factoren, waarvan de productie het gevolg is, kwantitatief doet varieeren. Schr. onderscheidt drie beschonwingswijzen, n.l. die van de totale opbrengst, gemiddelde opbrengst (opbrengst per eenheid) en meeropbrengst. Schr. geeft het verloop dezer opbrengsten aan, in de productie in het algemeen en in de industrie in het bijzonder. Hierbij wijst schr. er op, dat het in de praktiik niet noodig is, dat een periode met vermeerderende meeropbrengsten voorafgaat aan de verminderende meeropbrengsten.

In de praktijk beteekent voorts het varieeren met één productiefactor gewoonlijk onvermijdelijk het medefluctueeren van een of met andere iactoren. Treden twee of meer onafhankelijk variabele factoren op, dan wordt het onderzoek zeer bempeilijkt. Het blijkt, dat „één factor constant" tot een willekeurige keuze leidt. $\mathrm{Na}$ behandeling van voorbeelden van factoren van verschillenden aard in de industrie wordt speciaal de aandacht gevestigd op den factor in het minimum.

B a VI 1

De Ingenieur 16 Maart 1934. T.E. 2

De invloed van den ondernemingsvorm op de bedrijfszuinigheid bij overheidsbedrijven in het algemeen en gemeentebedrijven in het bijzonder

D ijker, R. A. - Het statistisch materiaal on een vergelijkende studie te maken is onvoldoende. Daarom gaat schr, uit van den invloed van den ondernemingsvorm op de efficientie. Het overheidsbedrijf heeft voor, dat zijn doelstelling rationeeler is, er is geen reden tot geheimhouding van zijn statistieken. T.o.v. bureaucratie. inefficientie van externe organen ( $B$. en $W$. en Raad t.o. commissarissen en aandeelhouders) verkeert het overheidsbedrijf niet onder nadeeliger omstandigheden dan het particulier bedriif. Wel is de verhouding tusschen bedrijfsleiding en werknemers belangrijk ongunstiger dan in het particulier bedrijf

B a VI 3

Financieel Overheidsheheer 1 en 15 Januari 1935

Le contröle budgétaire

P e nglaou, Ch. - In deze vervolgartikelen over de budgetcontrôle worden beschreven de tot standkoming en de contrôleerende werking van de budgets.

$\mathrm{B}$ a VI 12

L'Organisation November/December 1934

\section{LEER VAN DE ARBEIDSVOORWAARDEN}

De meest doelnatige belooning van den arbeid in het landbouwbedrijf

V e r h a ge, dr. J. - Schr bepleit de toepassing van loonstelsels in den landbouw en meent, dat het Rowan-premiestelsel in de eerste plaats voor experimenteeren in aanmerking komt.

$\mathrm{B}$ a VII 3 Landbouwkundig Tïdschrift Januari 1935

\section{La fatigue et le rendement}

B l um e nthal, L. - Teneinde de oorzaken en gevolgen van vermoeidheid na te gaan, dienen studies gemaakt te worden betreffende de grootte der productie, den invloed van werkonderbrekingen, de door de werklieden ingenomen houdingen in den loop van een werkdag enz. $\mathrm{B}$ a VII 5

\section{b. BIJZONDERE BEDRIJVEN}

\section{LANDBOUW- EN CULTUURBEDRIJVEN}

De meest doelmatige belooning van den arbeid in het landbouwbedrijf

Verh a g e, dr. J. - - Schr. bepleit de toepassing van loonstelsels in den landbouw en meent. dat het Rowan-premiestelsel in de eerste plaats voor experimenteeren in aanmerking komit B b IV 2

Landbouwkundig Tijdschrift Januari 1935

\section{INDUSTRIE}

De toestand in de steenindustrie

Hardenbroek, A. H, van - Schr. hanteert een aantal gedetailleerde cijfers betreffende de steenindustrie, waaruit blijkt, dat na 1920 de veldovens door ringovens werden vervangen, waardoor de productie van straatklinkers en, zacht" terugliep van $60 \%$ tot $15 \%$ van de productie en die van ,hard" met het verschilpercentage steeg, bij groote uitbreiding van de totale productie. Schr. bespreekt den toestand in de kalkzandsteenindustrie en vervolgens dien van de ringovenbedrijven, welke hij beschuldigt van parasiteeren on de gemeenschap wegens onnoodige achterlijkheid. Exportmogelijkheden zijn gering, omdat steen weinig vrachtkosten kan lijden en juist hooge transportkosten veroorzaakt. Restrictieplannen werden overwogen, docht hadden de fout, een uniforme restrictie te willen toepassen. De saneering moet brengen de opheffing van de meest achterlijke bedrijven met behoud van de economische meest juiste bedruven.

B b V 10

Econ. Statistische Berichten 9 Januari 1935

De saneeringsovereenkomsten in het bakkersbedriji

A m m e r a a n, dr. B. - De saneeringsovereenkonst van 1932 is mislukt in haar pogen on liet bakkersbedrijf te saneeren. Ook van de nienw ontworpen overeenkonst verwacht schr. geen heil, omdat men ook thans weer zijn toevlucht neemt tot prijszetting in plaats van tot productiebeperking. Tot dit laatste wekt schr. op, omdat een sanepring onder vrije concurrentie klaarblijkelijk niet tot stand komt en bij een rationeele broodvoorziening de broodprijs cenige centen per K.G. lager zou kunnen zijn dan zij nu is.

Invloed van tarief op (munt) gasverbruik

Voog d, ir. J. G. en ir. D. T i n be r ge $13-$ Op grond van statische analyse concludeeren schrijvers, dat het verband tusschen gemiddeld gasverbruik en gasprijs zoodanig ligt, dat de gemiddelde muntgasverbriliker per jaar ongeveer eenzelfde bedrag afneemt, welk ook het gastarief is

B b V 19

Gasbelangen 20 Januari 1935

\section{BOEKENREPERTORIUII}

\section{A. ACCOUNTANCY}

\section{LEER VAN DE INRICHTINO}

Batardon, L. La comptabilité à la portée de tous. Paris, 1934.

Hakk, R. G. ter. Het powers ponskaartensysteem toegepast op de verkoop- en debiteurenadministratie van een groothandel in technische artikelen. Rotterdam, 1934.

Handy office book of system, form and method. New York, 1934

Walker, C. E. Accounting principles and bookkeeping procedure, advanced course. Toronto, 1934.

\section{LEER VAN DE CONTROLE}

Klebba, W. Einführung in die Revisionspraxis. Hannover, 1935.

\section{B. BEDRIJFSHUISHOUDKUNDE}

\section{a. ALGEMEENE BEDRIJFSHUISHOUDKUNDE}

LEER VAN DEN KOSTPRIJS EN DE PRIJSVORMING

Bartholomew, I. R., John D. Hayes and C. V. Leroy. Present value and annuity tables. Applied to bond values and any coupon. New York, 1935

Marquardt, Heinrich. Die Ausrichtung der landwirtschaftlichen Produktion an den Preisen. Zugleich ein Beitrag zur Theorie des verbundenen Angebots. Jena. 1934.

\section{LEER VAN DE FINANCIERING}

Bartholomew, J. R., John D. Hayes and C. V. Leroy. Present value and annuity tables. Applied to bond values and any coupon. New York, 1935

Curtis, R. and F. B. Winham. Fresh fields for investment. London, 1934. 